\title{
O "EU” QUE VACILA: ZUMBIFICAÇÃO E APAGAMENTO
}

\author{
Lis Yana de Lima Martinez ${ }^{134}$ \\ Lúcia Sá Rebello ${ }^{135}$
}

RESUMO: Este artigo pretende apresentar breves reflexões acerca de como o imaginário nacionalista criado na época das colonizações e sua influência na sociedade se expressa nas artes - no campo literário, no caso brasileiro, e da dança, no caso Argentino - trazendo como exemplos a vida e a obra de Luiz Gama e o documentário Tango Negro, The African Roots of Tango, do cineasta angolano Dom Pedro. Espera-se que com este texto seja possível problematizar o diálogo entre culturas por meio de exemplos tão distintos, mas que se complementam com tantas semelhanças. Para tanto, se introduz o processo de zumbificação e fantasmificação.

Palavras-chave: Zumbificação, negro, tango, Luiz Gama

RESUMEN: Este artículo tiene como objetivo presentar breves reflexiones sobre cómo el imaginario nacionalista creado en el momento de la colonización y su influencia en la sociedad se expresa en las artes - en el campo literario, en Brasil, y en la danza, en Argentina - trayendo como ejemplos la vida y el trabajo de Luiz Gama y el documental Tango Negro, The African Roots of Tango, del director de cine Dom Pedro. Se espera que con este texto sea posible discutir el diálogo entre culturas a través de estos ejemplos diferentes, pero complementarios con muchas similitudes. Por lo tanto, se introduce el proceso de zombificación y fantasmificación.

Palabras-clave: zombificación, negro, tango, Luiz Gama

Se grosseiro alveitar ou charlatão

Entre nós se proclama sabichão;

\footnotetext{
${ }^{134}$ Mestranda em Literatura Comparada pela Universidade Federal do Rio Grande do SulUFRGS.

${ }^{135}$ Doutora em Letras pela Universidade Federal do Rio Grande do Sul. Professora Associada do Departamento de Letras Clássicas e Vernáculas do Instituto de Letras da UFRGS.
} 
E, com cartas compradas na

Alemanha,

Por anil nos impinge

ipecacuanha;

Se mata, por honrar a

Medicina,

Mas voraz do que uma ave de rapina;

E n'um dia, si errando na

receita,

Pratica no mortal cura

perfeita;

Não te espantes, ó Leitor, da novidade,

Pois que tudo no Brasil é raridade!

Se os nobres d'esta terra, empanturrados, Em Guiné teem parentes enterrados;

E, cedendo á prosapia, ou duros vicios,

Esquecem os negrinhos seus patricios;

Se mulatos de côr

esbranquiçada, Jà se julgam de origem refinada, E, curvos á mania que os domina, Desprezam a vovó que é pretamina:

Não te espantes, ó Leitor, da novidade,

Pois que tudo no Brasil é raridade!

Luiz Gama 
O preceito escravagista delimitou etnias no imaginário de muitas nações como uma seleção determinista natural, quando se tratava, na verdade, de um conceito social e político. Características corpóreas, como a cor da pele, passaram a ser estimadas como indicadores sociais para o discernimento, a partir da ótica do escravizador, do que era belo e possuía potencial politico e, portanto, aceito. René Depestre relata que

a ideologia escravista codificou as categorias raciais (fetiches e categorias da produção mercante) como produtos da natureza, quando embora pertencessem essencialmente à sociedade e à sua história político-econômica. A cor da pele, a estrutura do rosto, a textura dos cabelos, elementos menos significantes do corpo humano, transformaram-se em mensagens sociais que, considerando apenas a aparência física do indivíduo, permitiam dizer a qual classe ele pertencia. Os caracteres genéticos, as expressões da maravilhosa dissemelhança da espécie humana, eram integradas, nas necessidades de comércio, a um mito semiológico que hierarquizou e regulou o valor dos homens a partir de sua cor (DEPESTRE, 1980, p. 10).

Foi a partir deste determinismo epidérmico que se constituiu o processo de "zumbificação" do negro na América. Durante o regime colonial da América Latina,

houve uma dupla metamorfose: a metamorfose clássica de uma relação social em uma relação entre coisas; a metamorfose de uma relação entre escravos e mestres (que já se encontrava na escravidão antiga) em uma relação, mais fetichizada, entre "negros" e "brancos" (DEPESTRE, 1980, p. 9).

Trata-se aqui da primeira acepção de zumbi e não da que há muitos anos permeia as indústrias cinematográficas e a própria literatura. Antes que se adentre à questão da vacilação do eu, há de se esclarecer que zumbi é esse que o negro se tornou nas Américas. Zumbi é uma palavra que deriva de nzumbi, vocábulo da língua da família banta chamada quimbundo. No Haiti, no contexto da religião vodoo, os feiticeiros praticantes de magia 
negra podem criar zumbis a partir da dominação da mente. Nesse sentido, o zumbi é, ao contrário dos livres agressores que são os zumbis contemporâneos, corpo que vaga sob o comando de outra mente que não a sua. Retirado de sua terra, de sua cultura e de sua gente (lembrando que o processo de escravização do negro se deu em diferentes regiões da África e atingiu inúmeras e diferentes tribos e povos), o negro errou sem direitos, sem espírito, sem cultura: era um ser invisivel.

Hoje, nos países da América (dita) Latina vê-se não apenas o histórico processo de "zumbificação", mas também seu reflexo, o contexto de silêncio em que subsistem as marcas culturais de influência africana. $O$ zumbi veio sofrendo um processo de constante apagamento, sem voz, vem a se tornar inexistente, fantasma de uma História.

Este artigo pretende problematizar o imaginário nacionalista criado na época das colonizações e sua influência na sociedade, expressa nas artes, no modo como a autoridade cultural negra vem sendo tratada. Não há, aqui, pretensão de trazer uma solução ou uma resposta teórica final, mas, se possivel, ampliar o diálogo sobre o tema.

\title{
O "EU” QUE VACILA
}

\author{
E podem colocar-se à \\ retaguarda \\ Os veteranos sábios da \\ influência; \\ Que o trovista respeita \\ submisso, \\ Honra, pátria, virtude, \\ inteligência. \\ Luiz Gama
}

As artes são reflexo do ambiente que as cercam, logo relatam um período histórico, como pensou uma sociedade e o modo como esta sociedade quis que sua identidade fosse interpretada. As artes são transportadoras de ideias e espaço para que ideologias sejam elencadas e discutidas. A literatura do Brasil colonial revela os discursos nacionalistas, que buscavam de instituir uma unidade local (um eu) em oposição à externa (um outro), criando uma fronteira cultural delimitada, um imaginário de totalidade e de fronteira perante as demais nações. O sujeito da nação brasileira, a partir do discurso nacionalista, foi formatado, dentro 
do campo social, político e imagético, como etnicamente branco e homem, e sua cultura era a cultura da nação. Negros e indígenas eram, portanto, seres aculturados:

O cidadão, diz Aristóteles, é quem toma parte no fato de governar e ser governado. Mas uma outra forma de partilha precede esse tomar parte: aquela que determina os que tomam parte. $\mathrm{O}$ animal falante, diz Aristóteles, é um animal político. Mas o escravo, se compreende a linguagem, não a "possui". A partilha do sensivel faz ver quem pode tomar parte no comum em função daquilo que faz, do tempo e do espaço em que essa atividade se exerce (RANCIĖRE, 2009, p. 16).

Em seus textos, Homi Bhabha avalia que, apesar da vontade de um imaginário unificado, o "outro" não estava menos dentro da própria nação do que entre nações. No entanto, a tentativa metonímica de se representar um todo, a nação, por uma parte silencia, mas não cancela todas as diferenças e desigualdades.

Acompanhando a movimentação sócio-política, as artes inscreveram ficções sociais como fatos sociais. Hoje, países da América (dita) Latina já conseguem perceber que, embora se tenha tido independência politica das suas respectivas colônias, seus valores culturais e o imaginário que a identidade colonial criou não desapareceram. Em muito, ainda se lê e se interpreta, como confronta Mukherjee (1996), os antigos textos canônicos da Europa a partir da ótica metonímica, mas já há uma movimentação para reler textos próprios em termos próprios (não importados), a partir da perspectiva de seu próprio local histórico, social e geográfico. Busca-se hoje, a autonomia de interpretar uma obra com ótica que não a do centro, i.e. o leitor, não é mais aquele sujeito homem e branco (MUKHERJEE, 1996, p. 62).

$\mathrm{Na}$ procura de denunciar os rótulos culturais produzidos pelos colonizadores, Said (1995) afirma que as falácias sobre os "mundos colonizados" foram empregadas para abrir caminho para o colonizador. A tradição de diferença e estranheza, a determinação de um "eu” e um "outro" foram distribuídas em discursos, inclusive na literatura, a fim de "provar" o papel de herói do colonizador que buscava transformar, em auxílio, o "outro" em "civilizado" e "moderno", ou seja, trazendo-o para as 
luzes dos padrões europeus. O uso da força bruta se justificava como a de um pai que castiga o filho para que melhor aprenda a lição.

É claro que Said fala do mundo oriental e muito pode se aplicar de suas considerações ao modo como os índios foram tratados, mas não ao modo como os negros foram tratados. O negro, ser inferior, não teria lição a aprender e deveria apenas se subjugar tendo sua cultura prévia e posterior silenciada pelo discurso escravocrata.

\section{ZUMBIFICADO E APAGADO NA HISTÓRIA}

Que mundo? que mundo é este?

Do fundo seio d'est'alma

Eu vejo... que fria calma

Dos humanos na fereza!

Vejo o livre feito escravo

Pelas leis da prepotência;

Vejo a riqueza em demência

Postergando natureza

[...]

Digam lá o que quiserem

Fale embora o maldizente;

Eu bem sei que tudo mente,

Sei que o mundo tem razão;

Se eu tivesse na algibeira

Alguns cobres, que ventura! -

Mudava o nome, a figura,

Ficava logo Barão!

Luiz Gama

Como visto a cima, a necessidade de uma imagem nacional total e sem relevos seguiu uma ótica histórica que observava "temporalidade linear e contínua", que se desdobra por fases consecutivas, "no interior de um sistema que vai integrando fatos e eventos até formar uma tradição discursiva". Assim, uma história literária que visa a equiparar "a série literária e a série social” e, de tal modo, promover a associação e fixação dos interesses do imaginário indenitário (MIRANDA, 1994, p. 32). A história literária brasileira se fez 
como progressivo processo de emancipação das formas oriundas da Metrópole. Aí onde se ordenam os parâmetros que, contraditoriamente, definem o sentido da história como realização da civilização, ou seja, da forma do homem europeu moderno. Assim é que a construção de uma identidade nacional brasileira aponta, sobretudo a partir do Romantismo, na direção do assujeitamento "esquizofrênico" ao imaginário europeu - Peri e Ceci no jogo ambíguo de afetos e valores , através de um exercício de retórica (in)verossímil que conduz à marginalização dos "desafetos nacionais” e, portanto, à sua deslegitimação. Fora de foco, fora da história - está traçado o não-lugar dos deslegitimados que, entre algo chamado Brasil e a imagem idealizada de um país recém emancipado politicamente no grito, teimam em tornar opaca a transparência que permita aos brasileiros verem e serem vistos (MIRANDA, 1994, p. 32).

O “assujeitamento 'esquizofrênico' ao imaginário europeu” fez de Peri um cavaleiro medieval mais do que um índio propriamente dito. No caso da obra de José de Alencar, fica claro o mimetismo, quando, encorajado pelo discurso colonial, o sujeito adota para si (Alencar adota para seu personagem) hábitos culturais, imagens, propósitos e princípios do colonizador. O resultado acaba por ser uma cópia incoerente e que contamina a cultura local sendo uma das estratégias mais eficazes do poder colonial sobre suas colônias (BHABHA, 1983, p. 35).

Assujeitamento que também significa o apagamento de toda e qualquer partícula cultural que se encontre fora do discurso nacionalista de pureza e unidade. Aqui se insere o exemplo de Luiz Gonzaga Pinto da Gama, poeta baiano, que nasceu livre, mas foi vendido como escravo. Também conhecido como Getulino, Luiz Gama, mesmo filho de mãe liberta e pai branco, foi feito escravo aos dez anos. Em uma de suas cartas ${ }^{136}$, o poeta explica como isso lhe fora acontecer:

Nasci na cidade de São Salvador, capital da província da Bahia, em um sobrado da Rua do Bângala, formando ângulo

\footnotetext{
136 Sua obra está disponivel em: $<$ http://www.dominiopublico.gov.br/pesquisa/PesquisaObraForm.do?select_action=\&co_a utor $=85>$.
} 
interno, em a quebrada, lado direito de quem parte do adro da Palma, na Freguesia de Sant'Ana, a 21 de junho de 1830, pelas 7 horas da manhã, e fui batizado, 8 anos depois, na igreja matriz do Sacramento, da cidade de ltaparica. Sou filho natural de uma negra, africana livre, da Costa Mina, (Nagô de Nação) de nome Luíza Mahin, pagã, que sempre recusou o batismo e a doutrina cristã. Minha mãe era baixa de estatura, magra, bonita, a cor era de um preto retinto e sem lustro, tinha os dentes alvíssimos como a neve, era muito altiva, geniosa, insofrida e vingativa. Dava-se ao comércio - era quitandeira, muito laboriosa, e mais de uma vez, na Bahia, foi presa como suspeita de envolver-se em planos de insurreições de escravos, que não tiveram efeito. Era dotada de atividade. Em 1837, depois da Revolução do Dr. Sabino, na Bahia, veio ela ao Rio de Janeiro, e nunca mais voltou. Procurei-a em 1847, em 1856, em 1861, na Corte, sem que a pudesse encontrar. Em 1862, soube, por uns pretos minas, que conheciam-na e que deram-me sinais certos que (...) tanto ela como os seus companheiros desapareceram. (...) Meu pai, não ouso afirmar que fosse branco, porque tais afirmativas, neste país, constituem grave perigo perante a verdade, no que concerne à melindrosa presunção das cores humanas: era fidalgo e pertencia a uma das principais famílias da Bahia de origem portuguesa. Devo poupar à sua infeliz memória uma injúria dolorosa, e o faço ocultando o seu nome. Ele foi rico; e nesse tempo, muito extremoso para mim: criou-me em seus braços. Foi revolucionário em 1837. Era apaixonado pela diversão da pesca e da caça; muito apreciador de bons cavalos; jogava bem as armas, e muito melhor de baralho, amava as súcias e os divertimentos: esbanjou uma boa herança, obtida de uma tia em 1836; e reduzido à pobreza extrema, a 10 de novembro de 1840, em companhia de Luiz Cândido Quintela, seu amigo inseparável e hospedeiro, que vivia dos proventos de uma casa de tavolagem, na cidade da Bahia, estabelecida em um sobrado de quina, ao largo da praça, vendeu-me, como seu escravo, a bordo do patacho "Saraiva". 
Assim como o poeta não ousa afirmar que seu pai era branco, seu pai não ousou afirmar que Gama fosse branco, porque tal afirmativa constituiria um grave perigo perante a ideia de verdade, de nação, de mundo do discurso escravocrata. $O$ pai do poeta não apenas não ousou ir contra esse imaginário como também lhe fez uso quando, necessitado de dinheiro, vendeu o filho, que até então tratara como seu semelhante, como escravo. A violência do discurso colonial se escreve justamente para dentro de sua própria nação, trata-se de um modo de enunciação contraditório que ambivalentemente reinscreve tanto colonizador e colonizado (BHABA, 1985, p 95).

Ao escrever as cartas, Luiz Gama se faz autor de sua história, da história de seu contexto histórico. A poesia do relato transcende a necessidade de um comprometimento jornalístico com a verdade e permite que o autor seja conhecido em sua subjetividade:

O que passa a importar (...) é exatamente a ótica assumida pelo registro e como seu autor a expressa. Isto é, o documento não trata de "dizer o que houve", mas de dizer o que o autor diz que viu, sentiu experimentou, retrospectivamente, em relação a um acontecimento (GOMES, 2005, p. 14).

O imaginário centralizador criado pelo colonizador não tem poder sobre sua memória, mas é criador de sua dor. Uma dor que não pode ser esquecida. Para Jaques Le Goff (2003) a memória é então "o antídoto do Esquecimento", e exemplifica, a partir da mitologia grega, que, quando no inferno órfico, o morto deve procurar evitar a fonte do esquecimento, não deve beber no Letes, mas, inversamente, sorver da fonte da Memória, que é a fonte de imortalidade. Assim, a poesia de Luiz Gama - que divulga o preconceito étnico na sociedade brasileira em suas poesias satíricas como nos versos "Eis aqui o Getulino, que no plectro anda mofino. Sei que é louco e que é pateta, quem se mete a ser poeta; que no século das luzes, (...) compram negros e comendas" - fora descartada de manuais da literatura brasileira e ainda hoje é pouco estudada e, portanto, tem pouca repercussão.

\section{TANGO NEGRO}


No meio da bulha,

Que os ares feria,

$\mathrm{O}$ velho, de gosto,

Contente sorria.

A testa esfregava

Co'a destra enrugada,

Nas largas ventrechas

Sorvia a pitada.

Com voz de soprano,

Fazendo trejeitos,

Alegre exclamava,

Batendo nos peitos:

"Oh vinde Aretino,

"Mozart e Rossini,

"Deixando a rebeca

"Também Paganini!

"Que todos patetas

"Aqui ficarão,

"Ao som retumbante

"Do meu rebecão! [...]"

Luiz Gama

O mesmo apagamento que há no Brasil, observável pelo exemplo da falta de bibliografia sobre a obra e a vida de Luiz Gama, ocorre na Argentina. A Argentina, como o território do continente americano como um todo, também teve seu período escravagista. Onde estão seus negros? Em Tango Negro, The African Roots of Tango, o diretor angolano Dom Pedro se propõe justamente a esta pergunta e, mais, a problematizar as influências do negro na construção da cultura do Tango na Argentina e no Uruguai. Para que o leitor melhor acompanhar o debate, serão trazidas como referência direta apenas as cenas que se encontraram no trailer do filme ${ }^{137}$, e ficará o convite para que assista a toda obra. A respeito da realização da obra, diz Dom Pedro, em entrevista ao Courrier des Afriques ${ }^{138}$ :

\footnotetext{
${ }^{137}$ Disponivel em: <https://youtu.be/b1OCMY06u7M>. Acesso em: 12 jun. 2016.

138 Disponivel em: <http://www.courrierdesafriques.net/2015/09/exclusivo-cinema-tangonegro-as-raizes-africanas-do-tango-dom-pedro-acredito-que-muita-gente-ainda-nao-admitiu-oupercebeu-que-o-tango-possa-ter-raizes-negras-oriundas-de-africa>
} 
Naturalmente, onde quer que eu esteja, tenho sempre Angola nas entranhas; consequentemente, pensar em dar um contributo para a evolução do meu país e, por afinidade, ao continente-mãe em que está situado, é uma missão a que não posso furtar-me. É para mim uma forma de prestar homenagem aos nossos que, um dia, foram desenraizados, ficando longe das suas terras ancestrais. Com efeito, quando olho para trás, apercebo-me de que nada foi improvisado nas minhas decisões; pois interrogo-me desde a infância. Sempre tive a impressão, sensações de que uma voz silenciosa me falava e me orientava para as minhas reflexões! Não tenho aliás qualquer dúvida sobre isso; Acredito nisso profundamente. Com firmeza!

O regime escravocrata tornou etnocêntricas as relações entre os povos Americanos, fora e dentro das divisões políticas de países e criou, entre muitos outros, dois relevantes imaginários. O primeiro, de uma oposição entre uma América anglo-saxã, ao norte, e uma América negra e/ou mestiça, ao sul. O segundo, talvez produto do primeiro, um pensamento de "higienização" dos países ao sul que, então, se declararam culturalmente brancos. A presença africana nas culturas da América é silenciada "como se, antes do tráfico negreiro, além das culturas ameríndias, houvesse culturas greco-latinas ou anglo-saxãs já bem estruturadas nos espaços americanos nos quais, muito tempo depois, a África "selvagem" se teria mediocremente inserido" (DEPESTRE, 1980, p. $5)$.

Assim, expressões culturais na América foram por anos teorizadas a partir do olhar europeu. Os doces de Pelotas, cidade do sul do Brasil, são ditos receitas de origem portuguesa mesmo que entre eles esteja o quindim, por exemplo, doce que provém de um rito religioso á Oxum. Mesmo o carnaval brasileiro - claramente uma festa que, ao tirar pelo nome, obteve mais influência dos negros que vieram para o país do que de Veneza - é visto em sua suposta exclusiva origem italiana. $O$ tango em nada se diferencia dos doces e do carnaval brasileiro, é tratado como uma dança cuja herança é meramente ibérica.

A questão epidérmica é um tema controverso na Argentina, e assim nos diz uma voz no documentário. O país se considera branco e ignora a existência do negro e sua influência cultural. Grupos que tentam fazer 
visivel a identidade coletiva afro-argentina tem que enfrentar como oponentes,

em primeiro lugar, a narrativa dominante da nação argentina, que enfatiza a brancura de seus integrantes e minimiza a existência e o rol histórico dos afro-argentinos, e, em segundo lugar, a um sistema de classificação racial que invisibiliza a presença, na sociedade atual, de indivíduos considerados fenotipicamente negros, construindo a categoria social de "negros" (entre aspas) que, fingindo ser só estigma social e cultural, dissimula uma clara discriminação racial para setores mestiços de baixos ingressos (FRIGERIO \& LAMBORGHINI, 2010, p. 159).

Muito semelhante, como pode ser observado no documentário, ao que acontece no Uruguai. Em um determinado momento se escuta a pergunta "para onde os negros foram?" (00:00:50 - 00:01:49), pergunta esta que resume a temática do documentário tanto no que tange ao conteúdo, como também à intensidade que carrega. A resposta, pode-se assim dizer, formada a partir de todo o vídeo, se apresenta ao espectador como uma nuvem de chuva que se teme por demonstrar trazer uma tempestade: os negros foram mortos. Morto no sentido de terem sido apagados, de serem inexistentes:

Junto com uma narrativa dominante da nação que enfatiza a sua brancura, um segundo fator contextual (...) é a existência de um sistema de classificação racial que operou, pelo menos em grande parte do século XX, na direção da desaparição contínua dos negros na sociedade argentina e o predomínio cada vez maior da brancura portenha. Primeiro, pela atribuição da categoria negro a uma quantidade cada vez menor de pessoas, invisibilizando certos traços fenotípicos (e, inclusive, nas histórias familiares, a determinados indivíduos que os possuem), permitindo, assim, um predomínio naturalizado da brancura portenha. Por outro lado, com a insistência de que a atualmente muito utilizada categoria "negro" (entre aspas) ou "cabecinha negra", atribuida a grande parte da população pobre e de pele escura não envolve uma 
dimensão racial, mas meramente socioeconômica. A classificação de uma pessoa como "não negra" se produz, então, através de um trabalho (no sentido sociológico de construção social da realidade) de invisibilização dos traços fenotípicos negros a um nível micro, que corresponde a nivel macro, com a invisibilização - também constante - da presença do negro na história argentina e de suas contribuições à cultura argentina (FRIGERIO \& LAMBORGHINI, 2010, p. 157).

Não mais zumbis, corpos sem mente e incapazes, mas fantasmas habitantes de uma fronteira de identidade intransponivel. É o processo de fantasmificação. A intolerância ignóbil demonstra que o tão buscado imaginário de uma identidade nacional homogênea, centralizada e pura, “'etnicamente purificada', só pode ser atingida por meio da morte, literal ou figurativa, dos complexos entrelaçamentos da história e por meio das fronteiras culturalmente contingentes da nacionalidade (nationbood) moderna" (BHABHA, 1998, p. 24).

Mais uma voz clama por ser ouvida e diz "é quase inacreditável que somos invisiveis, obvio que existimos!” (00:01:01 - 00:01:49), mas as marcas de uma colonização que reteve a mão de obra africana sob "uma dupla subserviência, econômica e psicológica, retificando e alienando a consciência dos trabalhadores" ainda é atuante (DEPESTRE, 1980, p. 9). Desde a época de sua chagada à América,

o ser humano africano, submetido a essa dupla pressão que o afastava de sua cultura, tornou-se um ser invisivel, um osso inominado da história, exposto dia e noite ao perigo de perder irreversivelmente os restos de sua identidade como homem. Recorre-se, habitualmente, ao conceito de alienação para qualificar esta fantástica perda-de-si inerente à situação do escravo (DEPESTRE, 1980, p. 9).

A representação da nação como se encontra - proveniente de um discurso que a caracteriza como branca, pura e europeia - impede a coexistência de culturas simultâneas e de mesma relevância. A propósito dos "afro-argentinos, enfatiza seu adiantado desaparecimento e a irrelevância de suas contribuições à cultura local e se caracteriza, além disso, por uma notável cegueira quanto aos processos de mestiçagem e hibridação 
cultural" (FRIGERIO \& LAMBORGHINI, 2010, p. 157). Mestiçagem e hibridação cultural que podem ser depreendidas das palavras "O tango é feito de três memórias, três tristezas. A tristeza do imigrante; a tristeza do gaucho, gente que vivia neste país; e, finalmente, a tristeza do negro, que não veio aqui como imigrante, mas que foi trazido aqui, deixando sua vida na África” (00:01:01 - 00:01:36).

\section{ARREMATE}

Se os nobres desta terra, empanturrados, Em Guiné têm parentes enterrados;

E, cedendo à prosápia, ou duros vícios,

Esquecendo os negrinhos seus patrícios;

Se mulatos de cor esbranquiçada, Já se julgam de origem refinada, E curvos à mania que domina, Desprezam a vovó que é pretamina: Não te espantes, ó Leitor, da novidade, Pois tudo no Brasil é raridade!

[...]

Se ardente campeão da liberdade, Apregoa dos povos a igualdade, Libelos escrevendo formidáveis, Com frases de peçonha impenetráveis; Já do Céu perscrutando alta eminência 


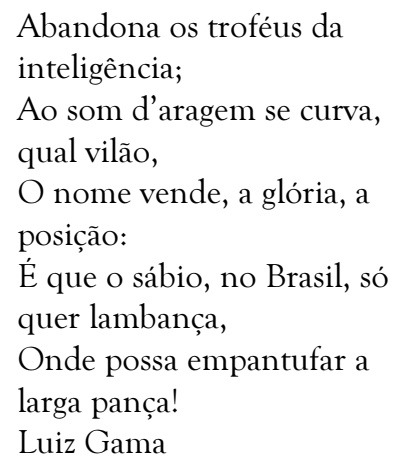

Em ambos os casos, fica visível a problemática do processo de identificação cultural, mas, talvez por estar transcrita quase que por inteiro acima, se faz mais visivel na carta de Luiz Gama. Trata de um processo duplo, entre culturas, que entra em conflito porque uma cultura inferioriza a outra. Como explicado por Homi Bhabha, "a diversidade cultural é também a representação de uma retórica radical da separação de culturas totalizadas que existem intocadas pela intertextualidade de seus locais históricos, protegidas na utopia de uma memória mítica de uma identidade coletiva única" (BHABHA, 1998, p. 63). A memória individual e coletiva passa pelos processos de lembrar, escrever e esquecer (GAGNEBIN, 2006). A intenção de Luiz Gama de buscar escrever na carta seu passado revela o sentimento de não pertencimento de um ser que se sente desconectado de suas origens.

O cineasta angolano Dom Pedro, capturando os relatos e as vozes já muito silenciadas e esquecidas, carregou a responsabilidade de fazer um manifesto aos habitantes e artistas da Argentina e do Uruguai, tendo seu documentário se tornado um mensageiro da causa da emancipação do imaginário de homogeneidade nacional criado ainda na época colonial. Um relato do hibridismo cultural, pois, o tango é fruto de

processos socioculturais nos quais estruturas ou práticas discretas, que existiam de forma separada, se combinam para gerar novas estruturas, objetos e práticas. Cabe esclarecer que as estruturas chamadas discretas foram resultado de hibridações, razão pela qual não podem ser consideradas fontes puras (CANCLINI, 2013, p. 19). 
Hoje, muito em função dos estudos pós-coloniais, iniciativas como a do cineasta Dom Pedro não são tão facilmente silenciadas. A teoria póscolonial emerge da insatisfação dos povos colonizados, como consequência de sua defrontação cultural e do amedrontamento de uma perda ainda maior de sua identidade cultural. Busca-se então

a emancipação de todos os tipos de subjugação definidos em termos de gênero, raça e classe. O pós-colonialismo, assim, não introduz um novo mundo livre dos males do colonialismo, a teoria sugere, em vez disso, continuidade e mudança” ${ }^{139}$ (RAI, 2005, p. 5).

Este artigo pretendeu apresentar breves reflexões acerca de como o imaginário nacionalista criado na época das colonizações e sua influência na sociedade se expressa nas artes no campo literário, no caso brasileiro, e da dança, no caso Argentino, trazendo como exemplos a vida e a obra de Luiz Gama e o documentário Tango Negro, The African Roots of Tango, do cineasta angolano Dom Pedro. Espera-se que com este texto tenha sido possível problematizar o diálogo entre culturas por meio de exemplos tão distintos, mas que se completam com tantas similitudes. Espera-se, ainda, que o processo de zumbificação e fantasmificação tenham sido explicados a contento e que o leitor interessado, a partir de seu locus de percepção, busque se aprofundar na teoria que consta nestas referências. Afinal, caro leitor, já diria Luiz Gama, em Guiné, temos parentes enterrados e somos netos de preta-mina.

\section{REFERÊNCIAS}

BHABHA, Homi K. O local da cultura. Belo Horizonte, Editora da UFMG, 2001.

BHABHA, Homi K. Signs takens from wonders: questions of ambivalence and authority under a tree outside Delhi. In: Critical Inquiry. Chicago, University of Chicago Press, 1985.

\footnotetext{
${ }^{139}$ N.T. (...) emancipation from all types of subjugation defined in terms of gender, race and class. Post-colonialism, thus does not introduce a new world which is free from ills of colonialism; it rather suggests both continuity and change.
} 
CANCLINI, Nestor Garcia. Culturas Hibridas: Estratégias para entrar e sair da modernidade. 4. ed. São Paulo: Editora da USP, 2008.

DEPESTRE, René. Bonjour et adieu à la négritude. Paris: Robert Laffont, 1980. 262 p. p. 82-160: Bonjour et adieu à la négritude. Disponível em: <http://www.ufrgs.br/cdrom/depestre/depestre.pdf〉. Acesso em: 12 jun. 2016.

FRIGERIO, Alejandro; LAMBORGHINI, Eva. Criando um movimento negro em um país "branco": ativismo político e cultural afro na Argentina. In: Afro-Ásia, 2010, p. 153-181.

GAGNEBIN, Jeanne Marie. Lembrar, escrever, esquecer. São Paulo: Ed. 34, 2006.

GAMA, Luiz. Primeiras trovas burlescas e outros poemas. São Paulo: Martins Fontes, 2000.

GAMA, Luiz. Primeiras trovas burlescas Disponivel em: <http://www.dominiopublico.gov.br/pesquisa/PesquisaObraForm.do?sel ect_action=\&co_autor=85>. Acesso em: 15 jun. 2016.

MIRANDA, Wander Melo. Projeções de um Debate. In: Revista brasileira de literatura comparada. Rio de Janeiro: Abralic, 1991.

MUKHERJEE, A. P. Post-colonialism: some uneasy conjunctures. In: Interrogation Postcolonalism: theory, text and context. Shimla: IIas, 1996.

RAI, G. Postcolonialism: its meaning and significance. In: The SPIEL jornal of English studies. Vol. 1, 2005.

RANCIĖRE, Jacques. A partilha do sensivel. São Paulo: Editora 34, 2009.

SAID, E. Cultura e Imperialismo. Rio de Janeiro, Companhia das Letras, 1995.

SAID, E. Orientalism. London, Penguin, 1995. 
Tango Negro: The African Roots of Tango. Dom Pedro, 2013, 93 min. Disponivel em: 〈https://youtu.be/b1OCMY06u7M>. Acesso em: 12 jun. 2016.

Recebido em: 29/06/2016

Aceito em: 15/07/2016 